\title{
A Vision for Hydrological Prediction
}

\author{
David A. Lavers ${ }^{1, *(\mathbb{D}}$, Maria-Helena Ramos ${ }^{2}\left(\mathbb{0}\right.$, Linus Magnusson ${ }^{1}$, Ilias Pechlivanidis ${ }^{3}(\mathbb{D}$, \\ Bastian Klein ${ }^{4}$, Christel Prudhomme ${ }^{1,5,6}$, Louise Arnal ${ }^{1,7}$, Louise Crochemore ${ }^{3}{ }^{(1)}$, \\ Bart Van Den Hurk ${ }^{8}\left(\mathbb{D}\right.$, Albrecht H. Weerts ${ }^{8,9}{ }^{(D}$, Shaun Harrigan ${ }^{1}$, Hannah L. Cloke ${ }^{7,10,11,12} \mathbb{D}$, \\ David S. Richardson ${ }^{1}$ (D) and Florian Pappenberger ${ }^{1}$ D
}

1 European Centre for Medium-Range Weather Forecasts (ECMWF), Shinfield Park, Reading, RG2 9AX, UK; linus.magnusson@ecmwf.int (L.M.); christel.prudhomme@ecmwf.int (C.P.); louise.arnal@ecmwf.int (L.A.); shaun.harrigan@ecmwf.int (S.H.); david.richardson@ecmwf.int (D.S.R);

florian.pappenberger@ecmwf.int (F.P.)

2 Université Paris-Saclay, INRAE, UR HYCAR, 92761 Antony, France; maria-helena.ramos@inrae.fr

3 Swedish Meteorological and Hydrological Institute, SE-60176 Norrköping, Sweden;

ilias.pechlivanidis@smhi.se (I.P.); louise.crochemore@smhi.se (L.C.)

4 Department M2-Water Balance, Forecasting and Predictions, Federal Institute of Hydrology (BfG), Am Mainzer Tor 1, 56068 Koblenz, Germany; klein@bafg.de

5 Centre for Ecology \& Hydrology, Wallingford, OX10 8BB, UK

6 Geography Department, Loughborough University, Loughborough, LE11 3TU, UK

7 Department of Geography and Environmental Science, University of Reading, Reading, RG6 6AB, UK; h.l.cloke@reading.ac.uk

8 Deltares, 2629 HV Delft, The Netherlands; bart.vandenhurk@deltares.nl (B.V.D.H.); albrecht.weerts@deltares.nl (A.H.W.)

9 Hydrology and Quantitative Water Management Group, Wageningen University \& Research, P.O. Box 47, 6700 AA Wageningen, The Netherlands

10 Department of Meteorology, University of Reading, Reading RG6 6UR, UK

11 Department of Earth Sciences, Uppsala University, SE-751 05 Uppsala, Sweden

12 Centre of Natural Hazards and Disaster Science, CNDS, SE-751 05 Uppsala, Sweden

* Correspondence: david.lavers@ecmwf.int; Tel.: +44-118-949-9467

Received: 11 February 2020; Accepted: 25 February 2020; Published: 28 February 2020

\begin{abstract}
IMproving PRedictions and management of hydrological EXtremes (IMPREX) was a European Union Horizon 2020 project that ran from September 2015 to September 2019. IMPREX aimed to improve society's ability to anticipate and respond to future extreme hydrological events in Europe across a variety of uses in the water-related sectors (flood forecasting, drought risk assessment, agriculture, navigation, hydropower and water supply utilities). Through the engagement with stakeholders and continuous feedback between model outputs and water applications, progress was achieved in better understanding the way hydrological predictions can be useful to (and operationally incorporated into) problem-solving in the water sector. The work and discussions carried out during the project nurtured further reflections toward a common vision for hydrological prediction. In this article, we summarized the main findings of the IMPREX project within a broader overview of hydrological prediction, providing a vision for improving such predictions. In so doing, we first presented a synopsis of hydrological and weather forecasting, with a focus on medium-range to seasonal scales of prediction for increased preparedness. Second, the lessons learned from IMPREX were discussed. The key findings were the gaps highlighted in the global observing system of the hydrological cycle, the degree of accuracy of hydrological models and the techniques of post-processing to correct biases, the origin of seasonal hydrological skill in Europe and user requirements of hydrometeorological forecasts to ensure their appropriate use in decision-making models and practices. Last, a vision for how to improve these forecast systems/products in the future was expounded, including advancing numerical weather and hydrological models, improved earth monitoring and more frequent interaction between forecasters and users to tailor the forecasts to
\end{abstract}


applications. We conclude that if these improvements can be implemented in the coming years, earth system and hydrological modelling will become more skillful, thus leading to socioeconomic benefits for the citizens of Europe and beyond.

Keywords: IMPREX; extreme hydrometeorological events; hydrological modelling; Numerical Weather Prediction; global earth observations; users

\section{Overview of Atmospheric and Large-Scale Hydrological Forecast Systems}

Hydrological forecasts are employed for many purposes. They are used, for instance, by civil protection authorities to prepare society for upcoming extreme hydrological events, such as floods and droughts; by reservoir managers to decide on releasing or storing water for a variety of uses (e.g., agriculture, hydropower, water supply); by watershed managers to anticipate drought risks and for navigation and aquatic ecosystems needs. A typical hydrological forecast system uses hydrometeorological observations to determine the initial hydrological conditions in (near-) real-time; weather forecasts of precipitation and other atmospheric variables to drive a hydrological and/or hydrodynamic model over a particular river basin; forecasters (experts) to evaluate model outputs, risks, and when necessary, issue warnings; a mechanism to communicate the hydrological forecasts and warnings to users and the public (including visualisation practices, dissemination channels and metadata, forecast products and services); a server to archive past and current forecasts; and evaluation protocols to assess the forecast quality and usefulness through post-event analyses. The hydrological model plays a key role in the forecast chain. It is the component responsible for representing surface physical characteristics, accounting for human impacts in surface and groundwater flows within the catchment, and linking river catchment topography, landscape, soil types, land use and storages to river flows. It transforms precipitation into runoff and propagates it through the river network to predict the river discharge in space and time. By integrating processes evolving in space and time within the river basin boundaries, from its headwaters to its outlet, a reliable hydrological model may become a main source of skill for flood forecasting (e.g., by taking into account river levels and soil moisture conditions before a storm affects the catchment), drought risk assessment (e.g., by taking into account groundwater levels and recharge), and water reservoir management (e.g., by taking into account seasonal snow storage and melting).

A key aspect of hydrological forecasting is the driving meteorological forecast. Weather forecasting is achieved through a process known as Numerical Weather Prediction (NWP), whereby, based on observations of the initial state (or conditions) of the atmosphere, numerical models that describe atmospheric and oceanic motions are integrated to determine future weather conditions [1]. For skillful NWP forecasts, it is essential to have a global observation network, including, for example, low Earth orbit and geostationary satellites, aircraft, radiosondes and ocean buoys. These observations are blended into NWP models in a procedure called data assimilation to generate the initial atmospheric conditions from which the weather forecasts are run for a given forecast time horizon. As the future evolution of weather conditions may be very sensitive to uncertainties in the initial atmospheric conditions and because of errors in the numerical model formulations, an ensemble of weather forecasts is often created. This ensemble is used to estimate the probability of future weather events and quantify the degree of (un)certainty of the forecast. There are multiple time horizons that can be targeted by the forecasts: From the short-range (hours to 3 days ahead), to the medium-range (3-15 days ahead), to the subseasonal scale (up to eight weeks ahead), up to seasonal time scales (several months ahead). Meteorological centres provide operational weather forecasts over these time horizons for several quantities: Land and sea surface temperatures, pressure, humidity, wind, cloud cover, precipitation (rainfall and snow) and others. Surface temperature and precipitation are the quantities that most hydrological models need to produce hydrological forecasts. Weather forecasts 
are produced in grids covering the whole Earth and can be found at different temporal scales (hours to months) and spatial scales (grid resolutions of several square meters to kilometres). Hydrological models can be run at the scale of small (a few kilometres) to large (thousands of kilometres) hydrologic units or river catchments and may cover entire countries or continents depending on specific model setups and targeted users.

Today, several systems run on a pan-European scale to deliver probabilistic weather and river flow forecasts. One such system is the operational Early Warning System (EWS) for floods of the Copernicus Emergency Management Service (CEMS), called the 'European Flood Awareness System' (EFAS; [2,3]). The development of EFAS started within a research programme of the European Commission in 2002 and has been running operationally at the European Centre for Medium-Range Weather Forecasts (ECMWF) since 2012. It uses weather forecasts from several NWP models and a hydrological model to provide early information on potential upcoming floods in Europe to national flood forecasting agencies and the European Civil Protection and Humanitarian Aid Operations. Given its proven usefulness for forecasting early signs of flooding, sometimes up to two weeks ahead, the EFAS forecast horizon was extended during the IMPREX project. Therefore, currently, EFAS forecasts are produced operationally up to seven months ahead for research purposes [4], and given research results showing its skillfulness are communicated to EFAS users through an operational outlook platform online for a forecast horizon of eight weeks. Figure 1 illustrates how these two forecast horizons are presented in the EFAS-CEMS hydrological service. It shows EFAS flood warnings over Europe with a 10-day forecast horizon (left panels) and an EFAS hydrological outlook for up to 8 weeks (right panels) for a forecast initialized on the 01 June 2019. We can see that users can enhance their decision-making by focusing on the early flood warnings of an upcoming event (e.g., blue colours across eastern Europe in Figure 1), thus gaining awareness of the expected hydroclimatic conditions (e.g., river levels above or below normal) in their catchments of interest and/or in the surrounding regions over the following weeks. This combined medium- to long-range information can be especially useful when dealing with a potential series of events or occurrences of floods, when managing water resources use in transboundary river basins, or to support the strategic planning of EU-wide emergency operations.

There has been an increasing interest in the implementation of large-scale months-ahead hydrological forecasting systems to serve the water sector. Further examples at the European scale are the pan-European hydroclimatic seasonal forecasting service from the Swedish Meteorological and Hydrological Institute (SMHI; based on the hydrological model E-Hype [5]), and the EDgE project end-to-end demonstrator for improved decision-making in the water sector [6,7] (based on the Mesoscale Hydrologic Model (mHM) [8], PCR-GLOBWB [9], Variable Infiltration Capacity (VIC) [10] and Noah-MP [11]), both developed under the Copernicus Climate Change Service (C3S) to support society and European authorities with consistent climate data and enhanced information on impacts. At the global scale, the global operational seasonal hydrometeorological forecasting system, GloFAS-Seasonal (based on the one-way coupled HTESSEL and Lisflood models) [12] and the global system based on the North American Multimodel Ensemble (NMME) [13] are examples of recent developments. Continental and global systems can address various user needs, notably in areas of sparse observational networks. Since they are based on global climate datasets, they also offer consistency among the meteorological data used in the setup and running of catchment-based hydrological models, even though they may lack accuracy at local scales due to local anthropogenic influences that are not usually taken into account in global models [14].

Although often accompanied by stakeholders' consultation and user needs assessments, large-scale hydrological forecast systems have not yet been thoroughly validated in real-time, operational conditions. Besides, they often lack a comprehensive analysis of the main drivers of hydrological forecast skill (e.g., what influences forecast performance and how performance can be improved to go beyond climatological information and increase the accuracy and usefulness of hydrological predictions). These were also aspects investigated in the IMPREX project. The lessons and weaknesses identified during the project are summarised in Figure 1. 


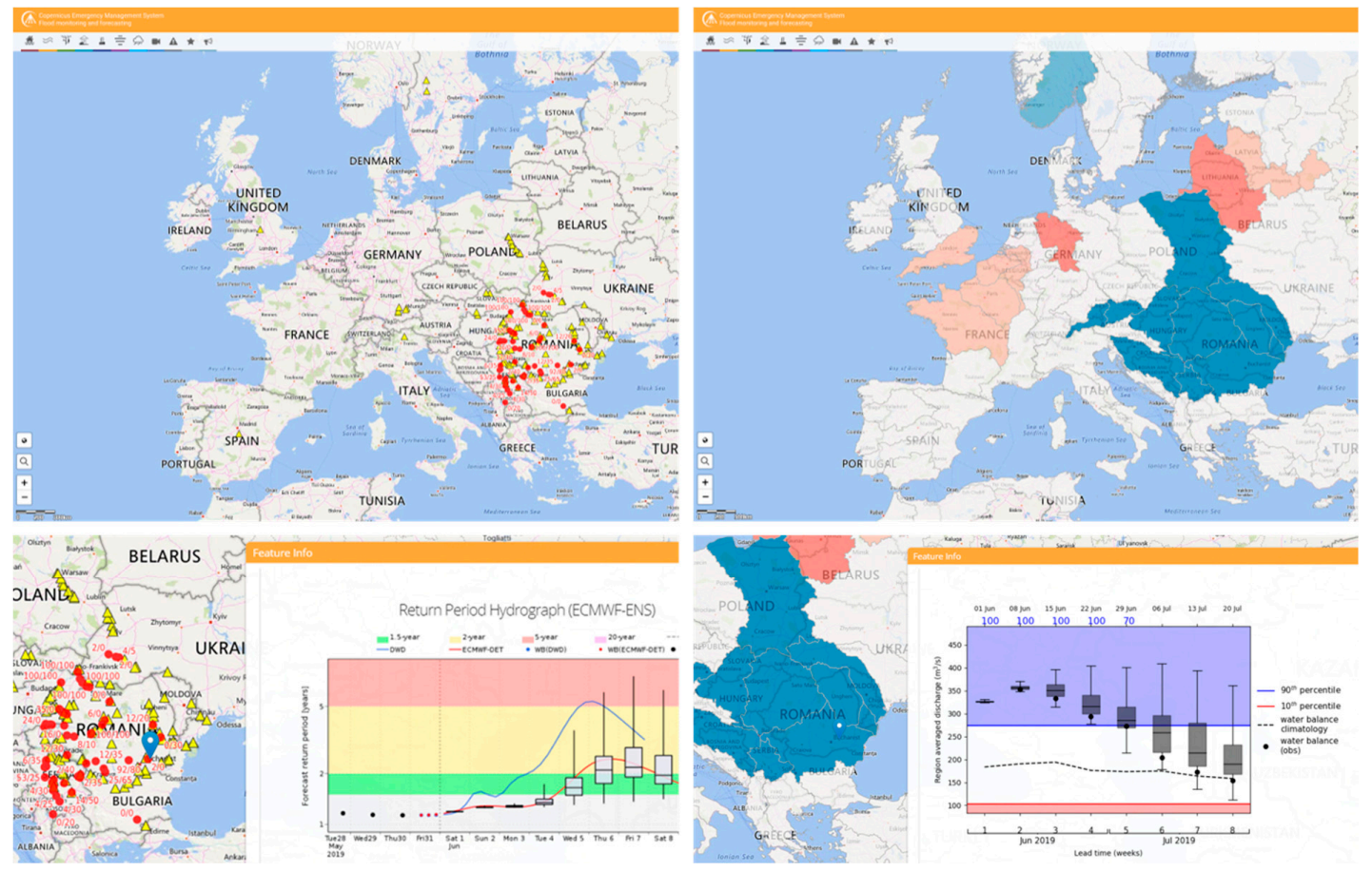

Figure 1. An example of four screenshots from the European Flood Awareness System (EFAS) system at the two forecast horizons: (left) Medium-range (10-day) forecasts showing a map (top) of the reporting points where the system forecasts exceedances of flood thresholds, and (bottom) an example hydrograph forecast at a river location in Romania (10-day forecasts issued on 1 June 2019). (right) The sub-seasonal (eight-week) EFAS outlook (top) showing areas with flows forecasted to be above the 90th percentile (blue) and below the 10th percentile (red) of river climatology, and (bottom) example boxplots of ensemble discharge predictions for a region encompassing parts of Romania, Bulgaria and Serbia (eight-week forecasts issued on 01 June 2019).

\section{Main Lessons and Weaknesses Identified Toward Improving Hydrological Prediction}

Although hydrometeorological forecast skill is improving gradually, probabilistic forecasting systems can still present biases due to their limitations in representing local processes and real-time conditions that influence the evolution of river flows and extremes. These biases can affect the quality of the forecasts in terms of reliability, sharpness and accuracy, meaning that users not only need to develop or adapt their procedures to ingest probabilistic forecast information into their decision-making procedures, but they also need to employ techniques to consider these imperfections of the forecasts. In this section, we highlight four main aspects arising during the IMPREX project. We believe these deserve careful attention from the forecasting and user communities in order to improve the quality and usefulness of hydrological predictions in the future.

\subsection{Gaps in Global Observed Data}

The global hydrological cycle describes the circulation of water through the atmosphere, land, rivers, lakes and oceans. In coupled hydrometeorological NWP models, its two main branches are represented by the atmospheric branch, which mostly consists of evapotranspiration, water vapour fluxes, condensation and precipitation, and the terrestrial branch, which focuses on the movement and storage of water in continents and oceans. For both branches, modelling efforts rely on global observations, which consist of a complex system of surface- and space-based sensors (e.g., in situ stations, radar, rain and river discharge gauges, satellite, radiosondes) owned and operated by national and international agencies.

There are many gaps in global observation coverage, which, in turn, affect hydrometeorological forecasting and its quality. For example, there are spatial gaps in hydrological records stored in 
hydrological databases such as the Global Runoff Data Centre, and downward trends in river flow data availability have been observed since the 1980s. An IMPREX-led study by Lavers et al. [15] highlighted this issue by comparing the lack of data sharing in the hydrological sciences to the NWP community, a situation partly arising from geopolitical contexts and the voluntary nature of the data upload process [15-17]. In addition to the challenges of maintaining large hydrological data archives, hydrological data must also be updated in unstable rivers. Extreme flows may cause changes in riverbed morphology which, in turn, cause changes in the river stage-discharge relation, introducing nonstationary behaviours in the data time series [18]. These issues not only reflect the challenges related to assessing historic data for the calibration of flood forecasting models, but also to using real-time data to update forecasting models with river runoff conditions before issuing a hydrological forecast.

In terms of the atmosphere, many data sparse regions exist, especially over the global oceans. A diagnostics study undertaken in IMPREX identified errors in the atmospheric branch of the global hydrological cycle [19]. Using ECMWF medium-range forecasts and unique flexible dropsonde observations (measuring atmospheric pressure, temperature, wind and humidity) deployed from research aircraft, the assessment showed that the source of the largest uncertainties in the flux of water vapour over the northeast Pacific Ocean was due to the winds above the planetary boundary layer, i.e., at about 1-1.5 $\mathrm{km}$ of altitude. As such, accurate wind observations over the ocean made regularly would benefit the modelling of the global hydrological cycle.

The paucity of global surface observations of the terrestrial branch of precipitation and river discharge (and the unknown anthropogenic influences, such as irrigation and reservoir regulation) hamper the undertaking of many verification studies at the global scale. Currently, there is sparsity in spatiotemporal coverage (e.g., fewer precipitation gauges or radar imagery in mountainous regions), a lack of consistent global discharge datasets and inadequate hydrometeorological data sharing between countries (e.g., a lack of standardisation protocols and legal and financial mechanisms to support shareable databases). As a consequence, it is currently not possible in many regions to accurately evaluate the skill of predictions from coupled large-scale hydrometeorological models. An example is given by the ongoing efforts toward building a global dataset of (near) real-time daily discharges. Discharges come from the GloFAS-ERA5 river discharge reanalysis dataset based on runoff from the ECMWF ERA5 global reanalysis coupled to a hydrological and river routing model. It thus corresponds to a proxy for observed discharges and has the advantage of offering a coherent and homogeneous vision over the entire globe, providing a unique benchmark dataset against which to verify the forecast skill and identify key areas for model improvement (Figure 2; [20]).

The performance of large-scale hydrological predictions for local (catchment-based) applications in the water sector needs particular attention, acknowledging the fact that it varies widely according to the physiographic characteristics of the location, the use of water resources in space and its variability in time (e.g., storage, diversions, withdrawals) and users' needs for information in their decision-making process (e.g., nature of information and resolution). Pathways for facing these challenges have recently merged. For instance, in IMPREX, a high-resolution (both temporally and spatially) dataset of area-average precipitation, temperature and potential evapotranspiration (based on satellite downwelling shortwave radiation) was developed for the Rhine River and used to verify the ECMWF ensemble weather forecasts [21,22]. These high-resolution datasets have the advantage of better representing the heterogeneities that are not captured by the relatively coarse grid scale of the atmospheric model. 


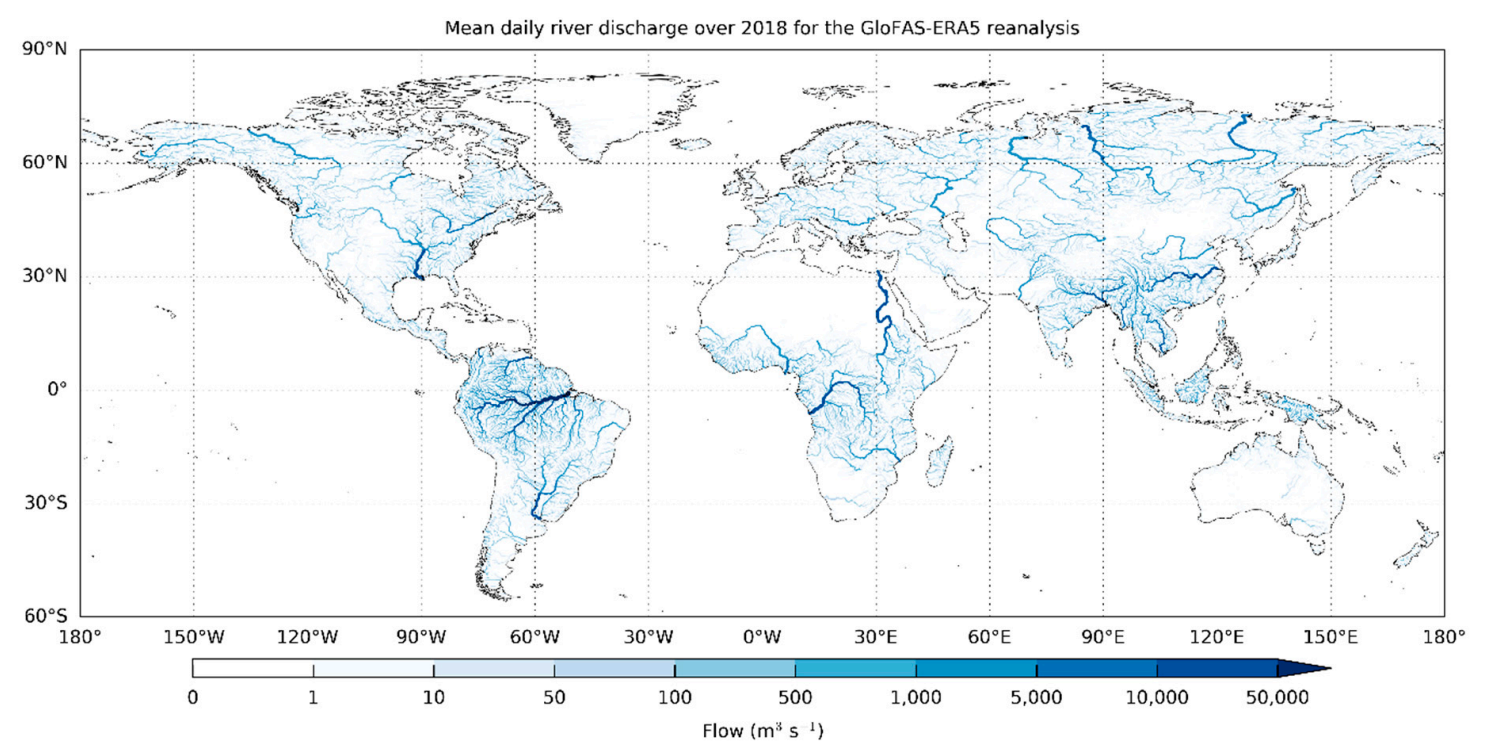

Figure 2. Mean daily river discharge over 2018 for each GloFAS river grid cell with an upstream area greater than $1000 \mathrm{~km}^{2}$ for the GloFAS-ERA5 river discharge reanalysis. Darker blue river sections have larger river discharge. Data can be freely downloaded from 1979 to (near) real-time from the Copernicus Climate Change Service (C3S) Climate Data Store (CDS): https://cds.climate.copernicus.eu/ cdsapp\#!/dataset/cems-glofas-historical?tab=overview.

\subsection{Hydrological Model Biases and Post-Processing}

The application of medium- and long-range NWP ensemble forecasts in water sectoral applications in IMPREX showed several shortcomings in the hydrometeorological forecasting chain. First, NWP ensemble forecasts from global models are often biased and have prediction intervals that are too narrow for surface variables of interest to hydrology, such as precipitation. These biases typically propagate through to the hydrological forecasts, and the lack of adequate ensemble spread is exacerbated after weather forecasts are processed through the hydrological model $[23,24]$.

Second, especially in low flow conditions, forecast errors are dominated by (systematic and statistical) uncertainty in the hydrological model and the initial conditions (soil moisture, reservoir water level and snowpack). To improve the estimation of the initial conditions of the hydrological model, and thus improve the hydrological forecasts, data assimilation methods (most commonly based on the Ensemble Kalman Filter approach) are applied. Another way to improve hydrological forecasting skill is to improve hydrological modelling (e.g., using better historical forcing datasets), which Imhoff et a.1 [25] investigated for the Rhine River as part of IMPREX. Finally, statistical post-processing methods, which mainly aim to increase reliability of probabilistic predictions (e.g., Bayesian Model Averaging, BMA; Ensemble Model Output Statistics, EMOS), have also been applied to hydrological ensemble forecasts to reduce biases in the output $[3,26]$ prior to IMPREX. It is only when a well-calibrated predictive uncertainty is provided to the end-user that rational decision-making based on a cost-benefit analysis is possible. For instance, when an IMPREX-led study used seasonal hydrological forecasts from the pan-European forecasting system E-HYPE for hydropower reservoir management in Spain, we found that raw forecasts could not be directly applied to the optimization models defined for the Jucar river system due to their strong biases. We observed that the complex hydrological behaviour of the river basin was not adequately reproduced by the pan-European model. A post-processing method was developed and applied to correct for the biases and bridge the gap between the local and the pan-European scales. The post-processing method relied on first comparing the E-HYPE pan-European discharges without accounting for human influence, obtained with historical meteorological forcing, to the impaired (human-influenced) discharges of the Jucar river basin using fuzzy logic. Once fuzzy logic systems were trained and validated for all subbasins, they were then applied (via a fuzzy 
inference) to the pan-European seasonal forecasts of the Jucar River Basin in order to obtain bias corrected discharge forecasts that could be applied to local models of reservoir optimization [27]. In another IMPREX study, we highlighted how the differences and the specificities of local and continental models raise the question of how useful large-scale models can be for local decision-making and how to optimally use the information from these different sources [14].

Third, in an attempt to assess seasonal forecasting skill, different hydrological model configurations in terms of se-up and model structure, complexity and spatial resolutions (lumped, semi-distributed and distributed) were further combined. Different post-processing methods (i.e., BMA, EMOS, equal weighting) have been applied to weight the individual model outputs, finally resulting in a multimodel average output of superior skill (particularly, for extreme flow forecasting) than each individual hydrological chain. In the case of the post-processing of continentally and regionally calibrated models, no model shows superior performance. An IMPREX study [28] developed a sensitivity analysis to isolate the relative contributions of errors in the initial hydrological conditions and the seasonal meteorological forcing to errors in the seasonal streamflow forecasts. This cost-effective method can easily be applied to any seasonal hydrological forecasting system to guide future system developments for tangible forecast improvements. The study also highlighted that further investigations are needed on how the interplay between uncertainties in the hydrological model (structural and parameter), land surface initial conditions (which affect system memory and predictability) and NWP forcing affect hydrological forecasting skill. Challenges remain on how to assess drivers of skill and predictability to enhance the quality of hydrological forecasting systems and foster their application to local water-related problems.

\subsection{Origin of Seasonal Hydrological Forecast Skill across Europe}

The seasonal forecasting skill for two pan-European hydrological systems (i.e., from the EFAS and the SMHI services) was evaluated during IMPREX [4,29]. Results showed these forecasts can have skillful seasonal predictions of anomalously high or low river flows (i.e., flows above or below average) in winter in Europe. However, a comparison with traditional seasonal river flow forecasting methods (i.e., methods based on historical observations of local meteorological conditions) showed that the use of NWP-based seasonal meteorological forecasts was only able to outperform these traditional methods in the first forecast month. This result reflects the limited skill of seasonal meteorological forecasts over Europe and suggests that knowledge of the initial hydrological conditions of the river basins (i.e., snowpack, soil moisture, streamflow and reservoir levels) and the more predictable, shorter forecast horizon in the atmosphere are important sources of predictability for seasonal streamflow forecasting over Europe. The evaluation also highlighted that improving seasonal meteorological forecasts would yield a larger improvement of the seasonal streamflow forecasts (compared to improving the initial hydrological conditions) beyond the first forecast lead month.

The IMPREX findings contributed to better understanding of the sources of skill in seasonal predictions, in turn identifying potential obstacles to improved seasonal hydrological predictions. Regions in Europe where users could benefit from improved seasonal meteorological forecast systems for hydrological forecasting were generally found in a wet hydroclimate, such as western Norway, Ireland, United Kingdom, northern Spain, the Alps, Italy, and the eastern shore of the Black Sea. Interestingly, research found that the areas with skillful seasonal streamflow forecasts were not necessarily collocated with regions of the highest forecast skill of seasonal precipitation and temperature. This can occur in catchments when the dominant source of predictability is from the initial hydrological conditions rather than the meteorological component of the forecasting system, highlighting the importance of using improved hydrological models and their initial conditions in the hydrometeorological seasonal forecasting chain. 


\subsection{User Requirements for Hydrometeorological Forecasts at Seasonal Time Scales}

A mismatch between the low skill currently available in (calibrated) seasonal meteorological forecasts and the high expectation from the user community for hydrometeorological forecasts at such lead times has become clear throughout the IMPREX project. The communication of forecast uncertainty proved to be an essential step and remains a challenging one. Decision-making in many water-related sectors is not fully developed to consider probabilistic (or ensemble) scenarios, and it is only when water managers and stakeholders have confidence in forecast quality and uncertainty that they will use them in their decision-making [30]. The interactions between forecast providers and users during sectoral applications of hydrometeorological forecasts provide a good basis for evidence on the usefulness of these forecasts. With the growing number of climate services issuing forecasts and outlooks on future climate and water resources, a new challenge for producers and users is the joint evaluation of the strengths and weaknesses of the different hydrometeorological forecasts issued by various systems and sources. Such evaluation comprises skill (quality) and value (economical or societal) of forecasts when these are effectively used to make decisions that might impact activities at short- or long-term horizons. We undertook these types of evaluation in IMPREX sectorial case studies and they are reported in the portfolio of factsheets provided by the project. The types of evaluation are referred to as: (i) Innovative Approaches for Flood Risk Assessment, (ii) Hydrometeorological Forecasting, (iii) Hydrometeorological predictions for the hydropower sector, (iv) Urban Water Supply Systems, (v) Drought Preparedness, Mitigation and Management and (vi) Improved Forecasting and Risk Management for the Water Transport Sector [31]. There is a challenge in assessing which forecast system best aligns with a user's requirement for informed decision-making on future hazardous conditions. It is important to recognise that forecast skill is dependent on the user group and a forecast which may be judged as unskillful for a certain user may have utility (or value) to another. For instance, in IMPREX, we saw that the accuracy of river flow forecasts was crucial to model the complex water system of hydropower reservoirs in the Jucar River Basin in Spain. In the waterway transportation sectoral survey, accurate water levels were considered necessary for lead times shorter than 10-15 days, while weekly means of flows at 3-4 weeks ahead and mean flow tendencies for three months ahead were seen as useful information for planning by the navigation-related users in the Rhine River in Germany.

\section{Vision for the Future}

\subsection{Numerical Model Advancements}

An open question remains on the strength of coupling required between the atmosphere, land and ocean components in a forecast system. Bauer et al. [1] hypothesised that the coupling of more physical processes in NWP could lengthen the skilful forecast horizon and ultimately contribute to hydrometeorological prediction developments and improved forecast skill of high-impact extreme events. For example, this could be achieved through an efficient earth system data assimilation approach, a more adequate representation of physical processes, NWP and hydrological models with higher resolution and increasing computing power. Furthermore, we argue that data assimilation and modelling improvements would advance the concept of 'seamless prediction', providing more coherent forecasts across different temporal and spatial scales. All these efforts could improve hydrometeorological models, which would lead to advances in closing the water balance and better simulations of the whole spectrum of hydrological events (floods and droughts).

\subsection{Improved Earth Monitoring and Human-Water Modelling}

A fundamental requirement for the development of forecasting systems is the broadening of the global observing system through European and international collaboration. Increasing the number of observations is essential for all parts of earth system modelling, from initialising NWP and hydrological models to calibrating forecast outputs for user applications and evaluating forecasts. For example, satellite observations tailored toward low-altitude moisture and winds could yield improvements in 
forecasting the atmospheric branch of the global hydrological cycle, which would potentially lead to more skilful precipitation forecasts. The development of remote sensing methods for the subsurface compartment of the terrestrial branch of the hydrological cycle would be particularly valuable for understanding and modelling hydrological processes at the global scale for local applications. Also, the availability of satellite-derived observations of river discharge, for example, the Surface Water and Ocean Topography satellite mission due to launch in 2021 [32], could broaden the river gauging network. Furthermore, more precipitation and river discharge gauges and snow water observations are needed, based on both traditional in-situ monitoring and innovative sensor networks (e.g., crowdsourced hydrologic data, mobile sensors), to enhance our capacity for better characterizing local hydrological behaviour. Note that wider access to existing observations, that is, those data that are present but not currently shared in real-time, may also improve hydrometeorological forecast skill [15]. The World Meteorological Organisation (WMO) Hydrological Observing System (WHOS) for hydrological observations could potentially be the dissemination platform for this effort.

Information on anthropogenic influences, such as dams (e.g., volume and operating rules), is essential to represent large and potentially predictable impacts on hydrological discharge and associated extremes. Water reservoirs can store river flows and change the space and time dynamics of floods and droughts. Coupling hydrological models with reservoir management information can contribute to improving simulations and scenario-based risk assessments, which may include data on regulated dam releases during drought periods, maximum storage capacity for flood retention or objective filling curves for seasonal reservoir operations [33]. The challenges of modelling human regulated systems are numerous and include not only the representation of management activities, but also land-use interactions with climate and integration of impacts of human behaviour [34]. The current knowledge gaps hinder the evaluation of global hydrological forecast systems and prevent local applications from fully benefitting from the spatially and temporally coherent predictions that these systems can provide to inform decision-making. In regional water resources and risk management, the large-scale perspective given by global systems, when tailored to interact with local applications and concerns, could be a facilitator in the (sometimes conflictual) management of water resources and water-related risks across sectors, as well as in the understanding of the numerous interdependencies of the climate-water-energy and food nexus under global changing conditions.

\subsection{Interaction between Forecasters and Users to Improve Forecasts}

The approach needed for improved forecast skill requires information exchange and engagement between forecast providers and users. Improved forecasts will be used more often by stakeholders if there is regular interaction with modellers (e.g., on forecast developments/improvements), with increased feedback to modelling systems to complete the loop in the 'system-user' interface. Users in the water sector have different needs and expectations toward NWP-based hydrological forecasts. In many situations in Europe, these forecasts do not yet have the skill necessary for their immediate and routine use by water managers and stakeholders, especially at seasonal scales. Seasonal forecasts are often available from large datasets, which first require the adequate infrastructure and technology to transfer them to local applications. These forecasts often need to be post-processed, downscaled and bias-adjusted to the local climate and hydrological characteristics. Some sectors have in-house human and financial resources to conduct experiments with seasonal forecasts in real (or close to real) operational settings, but others need additional guidance, training and tools-all of which have a financial cost-from forecast and service providers. Despite the variety of situations, it is, however, largely recognized that forecast skill can be potentially improved and usefulness enhanced. We suggest that supporting the dialogue between service providers and users is a step forward to adding value to large-scale predictions and contributing to informed local decision-making. 


\subsection{From Early Warning to Early Action}

Extending forecast lead time is an overall goal to gain preparedness for extreme hydrological situations. Given the limited skill of seasonal predictions in Europe beyond lead times of two months, we strongly encourage that forecast providers and users explore the use of subseasonal forecasts together [35]. These forecasts are targeted at lead times of 2-6 weeks, and have shown some skill over Europe, originating from large-scale atmospheric teleconnections [36]. The use of subseasonal forecasts can be fostered by supporting showcase applications, where forecast providers and users interact through an operational platform and in person-to-person settings to build multimodelling approaches, visualise outlooks and impacts at different scales and coevaluate the performance of sub-seasonal forecast systems in a dynamical and cooperative way. This provides the opportunity for collaborative projects in which knowledge is exchanged between model developers and users. Opportunities will emerge to extract useful information at subseasonal scales, which will eventually be useful for improving the skill of seasonal forecast systems. Cooperation is essential to build confidence, promote sharing data and resources and foster transparency, comparison and openness in forecast-targeted experiments. Further benefits would include the provision of better understanding of hydrometeorological forecast skill limitations, users' familiarisation with forecast quality and the capability of users to make decisions conditional on the level of forecast accuracy. This may then lead to improvements in all parts of the earth system modelling chain and empower human response to predictions and management of extreme hydrometeorological events.

\section{Conclusions}

IMPREX was a four-year European Union Horizon 2020 project with the aim of improving society's ability to anticipate and responding to future extreme hydrological events in Europe across many sectors (flood forecasting, drought risk assessment, agriculture, navigation, hydropower, water supply utilities [37]). The research and surveys undertaken have (1) highlighted gaps in the global observing system of the hydrological cycle, (2) assessed forecast quality from large-scale to local applications and investigated ways to improve the usefulness of hydrometeorological forecasting systems, (3) uncovered the origin of seasonal hydrological forecast skill in Europe and (4) identified user requirements of forecast adaptation to better fit their decision-making models and practices. IMPREX research allowed us to identify ways to improve hydrological prediction in the future by including modelling advancements, wider earth system monitoring, and further interaction between forecasters and users to correct biases and tailor services to local needs. If these recommendations can be implemented in the coming years, we hypothesise that earth system and hydrological modelling will become more skillful, thus leading to socioeconomic benefits for the citizens of Europe and beyond.

Author Contributions: Conceptualization, D.A.L., M.-H.R., L.M., I.P., B.K., A.W., F.P.; writing-original draft preparation, D.A.L; writing-review and editing, All authors; visualization, L.A. and S.H. All authors have read and agreed to the published version of the manuscript.

Funding: This research was funded by the European Union Horizon 2020 Programme, grant number 641811 (IMPREX).

Acknowledgments: We thank the three anonymous reviewers whose comments helped to clarify and improve aspects of this article.

Conflicts of Interest: The authors declare no conflict of interest.

\section{References}

1. Bauer, P.; Thorpe, A.; Brunet, G. The quiet revolution of numerical weather prediction. Nature 2015, 525, 47-55. [CrossRef] [PubMed]

2. Thielen, J.; Bartholmes, J.; Ramos, M.H.; de Roo, A. The European Flood Alert System—Part 1: Concept and development. Hydrol. Earth Syst. Sci. 2009, 13, 125-140. [CrossRef] 
3. Smith, P.; Pappenberger, F.; Wetterhall, F.; Thielen, J.; Krzeminski, B.; Salamon, P.; Muraro, D.; Kalas, M.; Baugh, C. On the operational implementation of the European Flood Awareness System (EFAS). ECMWF: Reading, UK, 2016.

4. Arnal, L.; Cloke, H.L.; Stephens, E.; Wetterhall, F.; Prudhomme, C.; Neumann, J.; Krzeminski, B.; Pappenberger, F. Skilful seasonal forecasts of streamflow over Europe? Hydrol. Earth Syst. Sci. 2018, 22, 2057-2072. [CrossRef]

5. Donnelly, C.; Andersson, J.C.M.; Arheimer, B. Using flow signatures and catchment similarities to evaluate the E-HYPE multi-basin model across Europe. Hydrol. Sci. J. 2016, 6, 255-273. [CrossRef]

6. Wanders, N.; Thober, S.; Kumar, R.; Pan, M.; Sheffield, J.; Samaniego, L.; Wood, E.F. Development and Evaluation of a Pan-European Multimodel Seasonal Hydrological Forecasting System. J. Hydrometeorol. 2018, 20, 99-115. [CrossRef]

7. Samaniego, L.; Thober, S.; Wanders, N.; Pan, M.; Rakovec, O.; Sheffield, J.; Wood, E.F.; Watts, G.; Hisdal, H.; Estrela, T; et al. Hydrological forecasts and projections for improved decision-making in the water sector in Europe. Bull. Am. Meteorol. Soc. 2019. [CrossRef]

8. Samaniego, L.; Kumar, R.; Attinger, S. Multiscale parameter regionalization of a grid-based hydrologic model at the mesoscale. Water Resour. Res. 2010, 46, W05523. [CrossRef]

9. Sutanudjaja, E.H.; Van Beek, R.; Wanders, N.; Wada, Y.; Bosmans, J.H.; Drost, N.; Hoch, J.M.; Jong, K.; Schmitz, O.; Wisser, D.; et al. PCR-GLOBWB 2: A 5 arcmin global hydrological and water resources model. Geosci. Model Dev. 2018, 11, 2429-2453. [CrossRef]

10. Liang, X.; Lettenmaier, D.P.; Wood, E.F.; Burges, S.J. A simple hydrologically based model of land surface water and energy fluxes for GCMs. J. Geophys. Res. 1994, 99, 14415-14428. [CrossRef]

11. Niu, G.Y.; Yang, Z.L.; Mitchell, K.E.; Chen, F.; Ek, M.B.; Barlage, M.; Kumar, A.; Manning, K.; Niyogi, D.; Rosero, E.; et al. The community Noah land surface model with multiparameterization options (Noah-MP): 1. Model description and evaluation with local-scale measurements. J. Geophys. Res. Atmos. 2011, 116, D12109. [CrossRef]

12. Emerton, R.; Zsoter, E.; Arnal, L.; Cloke, H.L.; Muraro, D.; Prudhomme, C.; Stephens, E.M.; Salamon, P.; Pappenberger, F. Developing a global operational seasonal hydro-meteorological forecasting system: GloFAS-Seasonal v1.0. Geosci. Model Dev. 2018, 11, 3327-3346. [CrossRef]

13. Yuan, X.; Roundy, J.K.; Wood, E.F.; Sheffield, J. Seasonal forecasting of global hydrologic extremes: System development and evaluation over GEWEX basins. Bull. Am. Meteor. Soc. 2015, 96, 1895-1912. [CrossRef]

14. Crochemore, L.; Ramos, M.-H.; Pechlivanidis, I.G. Can continental model convey useful seasonal hydrologic information at the catchment scale? Water Resour. Res. 2020, 56, e2019WR025700. [CrossRef]

15. Lavers, D.A.; Harrigan, S.; Andersson, E.; Richardson, D.S.; Prudhomme, C.; Pappenberger, F. A vision for improving global flood forecasting. Environ. Res. Lett. 2019. [CrossRef]

16. Hannah, D.M.; Demuth, S.; van Lanen, H.A.J.; Looser, U.; Prudhomme, C.; Rees, G.; Stahl, K.; Tallaksen, L.M. Large-scale river flow archives: Importance, current status and future needs. Hydrol. Process. 2011, 25, 1191-1200. [CrossRef]

17. Do, H.X.; Gudmundsson, L.; Leonard, M.; Westra, S. The Global Streamflow Indices and Metadata Archive (GSIM) - Part 1: The production of a daily streamflow archive and metadata. Earth Syst. Sci. Data 2018, 10, 765-785. [CrossRef]

18. Mansanarez, V.; Renard, B.; Le Coz, J.; Lang, M.; Darienzo, M. Shift happens! Adjusting stage-discharge rating curves to morphological changes at known times. Water Resour. Res. 2019, 55, 2876-2899. [CrossRef]

19. Lavers, D.A.; Rodwell, M.J.; Richardson, D.S.; Ralph, F.M.; Doyle, J.D.; Reynolds, C.A.; Tallapragada, V.; Pappenberger, F. The Gauging and Modeling of Rivers in the Sky. Geophys. Res. Lett. 2018. [CrossRef]

20. Harrigan, S.; Zsoter, E.; Alfieri, L.; Prudhomme, C.; Salamon, P.; Wetterhall, F.; Barnard, C.; Cloke, H.; Pappenberger, F. GloFAS-ERA5 Operational Global River Discharge Reanalysis 1979-Present. Available online: https://www.earth-syst-sci-data-discuss.net/essd-2019-232/essd-2019-232.pdf (accessed on 12 December 2019). [CrossRef]

21. van Osnabrugge, B.; Weerts, A.H.; Uijlenhoet, R. genRE: A Method to Extend Gridded Precipitation Climatology Data Sets in Near Real-Time for Hydrological Forecasting Purposes. Water Resour. Res. 2017, 53, 9284-9303. [CrossRef]

22. van Osnabrugge, B.; Uijlenhoet, R.; Weerts, A. Contribution of potential evaporation forecasts to 10-day streamflow forecast skill for the Rhine River. Hydrol. Earth Syst. Sci. 2019, 23, 1453-1467. [CrossRef] 
23. Crochemore, L.; Ramos, M.-H.; Pappenberger, F. Bias correcting precipitation forecasts to improve the skill of seasonal streamflow forecasts. Hydrol. Earth Syst. Sci. 2016, 20, 3601-3618. [CrossRef]

24. Meißner, D.; Klein, B.; Ionita, M. Development of a monthly to seasonal forecast framework tailored to inland waterway transport in central Europe. Hydrol. Earth Syst. Sci. 2017, 21, 6401-6423. [CrossRef]

25. Imhoff, R.O.; van Verseveld, W.J.; van Osnabrugge, B.; Weerts, A.H. Scaling point-scale pedotransfer functions parameter estimates for seamless large-domain high-resolution distributed hydrological modelling: An example for the Rhine river. Water Resour. Res. 2020. submitted.

26. Bogner, K.; Pappenberger, F. Multiscale error analysis, correction, and predictive uncertainty estimation in a flood forecasting system, Water Resour. Res. 2011, 47, W07524. [CrossRef]

27. Macian-Sorribes, H.; Pechlivanidis, I.G.; Crochemore, L.; Pulido-Velazquez, M. Fuzzy post-processing of pan-European seasonal hydrological forecasts for river basin management. J. Hydrometeorol. 2020. under review.

28. Arnal, L.; Wood, A.W.; Stephens, E.; Cloke, H.; Pappenberger, F. An efficient approach for estimating streamflow forecast skill elasticity. J. Hydrometeorol. 2017, 18, 1715-1729. [CrossRef]

29. Pechlivanidis, I.G.; Crochemore, L.; Rosberg, J.; Bosshard, T. Which are the key drivers controlling the forecasts of seasonal streamflow volumes? Water Resour. Res. 2020. under review.

30. Lorenz, T.; Kramer, A. Towards More Action-Oriented Research and Climate Services, IMPREX Position Paper. 2019. Available online: https://www.imprex.eu/system/files/generated/files/resource/position-paper3bislessons-learntpdf.pdf (accessed on 12 December 2019).

31. IMPREX Factsheets. Available online: https://www.imprex.eu/publications (accessed on 12 December 2019).

32. Biancamaria, S.; Lettenmaier, D.P.; Pavelsky, T.M. The SWOT mission and its capabilities for land hydrology. Surv. Geophys. 2016, 37, 307-337. [CrossRef]

33. Dorchies, D.; Thirel, G.; Perrin, C.; Bader, J.-C.; Thepot, R.; Rizzoli, J.-L.; Jost, C.; Demerliac, S. Climate change impacts on water resources and reservoir management in the Seine river basin (France). La Houille Blanche 2016, 32-37. [CrossRef]

34. Wada, Y.; Bierkens, M.F.; De Roo, A.; Dirmeyer, P.A.; Famiglietti, J.S.; Hanasaki, N. Human-water interface in hydrological modelling: Current status and future directions. Hydrol. Earth Syst. Sci. 2017, 21, 4169-4193. [CrossRef]

35. Wetterhall, F.; Di Giuseppe, F. The benefit of seamless forecasts for hydrological predictions over Europe. Hydrol. Earth Syst. Sci. 2018, 22, 3409-3420. [CrossRef]

36. Ferranti, L.; Magnusson, L.; Vitart, F.; Richardson, D.S. How far in advance can we predict changes in large-scale flow leading to severe cold conditions over Europe? Q. J. R. Meteorol. Soc. 2018, 144, 1788-1802. [CrossRef]

37. van den Hurk, B.J.J.M.; Bouwer, L.M.; Buontempo, C.; Döscher, R.; Ercin, E.; Hananel, C.; Hunink, J.; Kjellström, E.; Klein, B.; Manez, M.; et al. Improving predictions and management of hydrological extremes through climate services: www.imprex.eu. Clim. Serv. 2016, 1, 6-11. [CrossRef]

(C) 2020 by the authors. Licensee MDPI, Basel, Switzerland. This article is an open access article distributed under the terms and conditions of the Creative Commons Attribution (CC BY) license (http://creativecommons.org/licenses/by/4.0/). 